\title{
1. Read a lot!
}

Many academics do not prioritise reading journal articles and keeping up to date with the literature. We all have competing demands on our time; if it is not teaching then it is teaching preparation, designing an appropriate research method, writing up results, redrafting papers, discussing ideas with co-authors, preparing to present research, etc.

Reading stimulates you mentally and gives you knowledge.

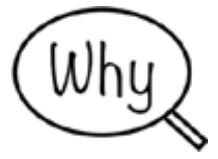
It encourages you to make links between areas of knowledge that you might not have done before. The longer the period of time that you do not read, the further you will fall behind the literature. Reading also updates contrasting arguments and can strengthen your analytical skills. Reading also improves your understanding of how to write an argument, and it will help you hone your writing skills. Do not only read papers in your particular research area, as reading around your subject area will enable you to re/discover what people are doing in other connected research areas, and those ideas may spill over into your own research area. Be cognisant of new methodological advancements and new ways of thinking. Read journals in connected disciplines (e.g. economists should read sociology and anthropology) to stimulate your mind to juggle contrasting thoughts. Read newspapers to discover examples. Read some old literature that may have been undervalued through the ages - you might imagine a contemporary understanding of a not hitherto appreciated idea.

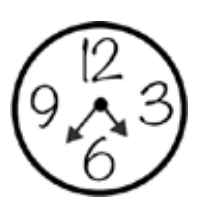

Read one paper every working day. If you enjoy it, then reading can help you relax. Sometimes the best time of the day to read is before you embark on your other duties. Some like to read immediately after lunch while others find it difficult to read after eating when they may feel drowsy and inattentive. Do not read so much that it stops you from writing or discussing content with others; after all, reading should complement your own writing, not replace it. Try to fit some reading into every working day and be flexible on the choice of paper depending on the amount of time that you have available; some papers are short and will only take 30 minutes to read while others will require much more time for cogitation. Do not try to shoehorn a complex paper into an hour's slot if this time constraint limits your ability to read and understand it fully. 


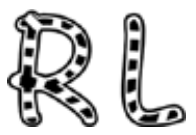

Research leaders could organise reading groups to encourage colleagues to draw out lessons from important papers. A good place to start is Ziliak and McCloskey's (2008) ${ }^{1}$ view on the Cult of Statistical Significance. Challenging texts stimulate lively, focused debate and greater knowledge sharing and engagement between colleagues. Research leaders should encourage colleagues to suggest texts that they think are important or contentious. They can also suggest texts that they wish to know others' perspectives on. Not everyone within a department will be interested in the same literature, so membership of reading groups should be fluid and inclusive, and address broad topics. If there are papers that a research leader thinks could be useful for specific colleagues, they should highlight those papers to their colleagues. The next step is for the research leader to emphasise to their colleagues that they would be interested in their perspective on a paper, and this would make the colleagues feel stimulated and respected.

\section{NOTE}

1. Ziliak, S. T. and McCloskey, D. N. (2008), The Cult of Statistical Significance, University of Michigan Press. 